\title{
PENGARUH STRATEGI SPONSORSHIP PT.GOJEK INDONESIA DI LIGA 1 INDONESIA TERHADAP KEPUTUSAN PEMESANAN GO-JEK DI KOTA PALEMBANG
}

\author{
Oleh : \\ Herman \\ Alumni Fakultas Ekonomi Universitas IBA \\ Esty Naruliza \\ Dosen Tetap Fakultas Ekonomi Universitas IBA
}

\begin{abstract}
PT. Gojek Indonesia (GO-JEK) was a firm engaged in the business of transportation based on application smart phone. GO-JEK do strategy sponsorship by become one of the main sponsors in the implementation of a football gojek traveloka ligal indonesia. With strategy sponsorship, how does it influence on reservations go-jek in palembang?

Sponsorship is the financial support from an organization, person, or activity in exchange for publicity and brand association.

The purpose of this research is to know how the influence of sponsorship strategy PT.Gojek Indonesia in league 1 Indonesia of the decision of reserving go-jek Palembang. The data used in this research was the primary data obtained from the data the questionnaire. Method of withdrawal of samples on this research using Cluster Sampling.

The results of this research indicate that is no significant influence against decisions ordering GO-JEK in Palembang. Testing is done based on the regression results table that indicates that the value $t_{\text {calculate }}>t_{\text {table }}(1,332>1.65)$.

the conclusion, the decision ordering GO-JEK in Palembang is affected by the sponsorship of $0.7 \%$. While the rest of $99.3 \%$ are other factors that are not included in this study such as quality of service, prices, methods of payment and the variety of products offered.
\end{abstract}

\section{Keywords: Sponsorship and decisions ordering}

\section{PENDAHULUAN}

Industri jasa merupakan salah satu industri yang semakin berkembang saat ini. Tak terkecuali pada industri penyedia jasa transportasi. Setiap orang menginginkan alat transportasi yang mudah didapat, cepat, aman dan nyaman. Salah satunya menggunakan jasa angkutan darat yang merupakan moda transportasi yang masih menjadi favorit di Indonesia. Permintaan yang besar menimbulkan industri angkutan darat ini menjadi industri yang menjanjikan. Banyak perusahaan angkutan darat mulai bermunculan dalam persaingan industri ini. Setiap perusahaan membuat strategi bisnis dan meningkatkan kualitas serta pelayanannya agar pertumbuhan bisnisnya tetap stabil. Perusahaan harus mampu melihat kebutuhan dan keinginan konsumen. Dalam pemasaran, produk yang dihasilkan oleh produsen berlaku prinsip pemuasan kebutuhan, keinginan dan permintaan konsumen. 
PT. Gojek Indonesia (GO-JEK) merupakan perusahaan yang bergerak dalam bisnis trasportasi angkutan darat. Dikutip dari www.go-jek.com, GO-JEK merupakan perusahaan angkutan darat yang menjadi pelopor (pioneer) dalam pengembangan bisnis angkutan darat online di Indonesia. GO-JEK didirikan tahun 2010 berawal sebagai perusahaan transportasi roda dua melalui panggilan telepon, GO-JEK kini telah tumbuh menjadi permintaan berbasis telepon genggam (on-demand mobile platform) dan aplikasi terdepan yang menyediakan berbagai layanan lengkap mulai dari transportasi, logistik, pembayaran, layan-antar makanan, dan berbagai layanan on-demand lainnnya. GO-JEK adalah sebuah perusahaan teknologi berjiwa sosial yang bertujuan untuk meningkatkan kesejahteraan pekerja di berbagai sektor informal di Indonesia.

Saat ini GO-JEK telah beroperasi di 50 kota di Indonesia, seperti Jakarta, Bandung, Surabaya, Bali, Makassar, Medan, Palembang, Semarang, Yogyakarta, Balikpapan, Malang, Solo, Manado, Samarinda, Batam, Sidoarjo, Gresik, Pekanbaru, Jambi, Sukabumi, Bandar Lampung, Padang, Pontianak, Banjarmasin, Mataram, Kediri, Probolinggo, Pekalongan, Karawang, Madiun, Purwokerto, Cirebon, Serang, Jember, Magelang, Tasikmalaya, Belitung, Banyuwangi, Salatiga, Garut, Bukittinggi, Pasuruan, Tegal,Sumedang, Banda Aceh, Mojokerto, Cilacap, Purwakarta, Pematang Siantar, dan Madura serta pengembangan di kota-kota lainnya pada tahun mendatang. GO-JEK memiliki 16 layanan yang ditawarkan pada konsumen lewat aplikasinya. Berikut layanan yang ditawarkan PT. Gojek Indonesia.

Tabel 1

Layanan GO-JEK di Palembang

\begin{tabular}{|c|l|l|c|}
\hline No & Layanan & \multicolumn{1}{|c|}{ Jenis layanan } & Keterangan \\
\hline 1 & Go- Ride & Angkutan penumpang sepeda motor & Tersedia \\
\hline 2 & Go- Car & Angkutan penumpang mobil & Tersedia \\
\hline 3 & Go- Bluebird & Pemesanan taxi & Tersedia \\
\hline 4 & Go- Food & Pesan antar makanan dan minuman & Tersedia \\
\hline 5 & Go- Send & Antar barang & Tersedia \\
\hline 6 & Go- Pulsa & Penjualan pulsa handphone & Tersedia \\
\hline 7 & Go- Shope & Belanja di toko non mitra GO-JEK & Tersedia \\
\hline 8 & Go- Mart & Belanja di toko mitra GO-JEK & Tersedia \\
\hline 9 & Go- Tix & Penjualan tiket bioskop dan even & Tersedia \\
\hline 10 & Go- Box & Mobil angkut barang & Tersedia \\
\hline 11 & Go- Massage & Pesan pijat profesional atau terapis & Tidak \\
\hline 12 & Go- Clean & $\begin{array}{l}\text { Membersihkan dan membereskan } \\
\text { rumah, kantor dll }\end{array}$ & Tidak \\
\hline 13 & Go- Glam & Perawatan kecantikan & Tidak \\
\hline 14 & Go- Auto & Tambal ban dan ganti oli kendaraan & Tidak \\
\hline 15 & Go- Med & Pesan antar obat-obatan & Tidak \\
\hline 16 & Go- Busway & $\begin{array}{l}\text { Antar penumpang ke halte trans } \\
\text { Jakarta }\end{array}$ & $\begin{array}{c}\text { Khusus } \\
\text { Jakarta }\end{array}$ \\
\hline
\end{tabular}

Sumber: www.go-jek.com (diakses 13/12/2017) 
GO-JEK menjadi salah satu sponsor utama dalam penyelenggaraan sepak bola nasional dengan tema GO-JEK TRAVELOKA LIGA 1 INDONESIA tahun 2016-2017. GO-JEK memilih mensponsori event sepak bola liga 1 Indonesia karena banyaknya penggemar olah raga sepak bola di Indonesia dimana tujuannya adalah untuk menciptakan kesadaran merk (brand awareness) kepada pasar di Indonesia yang sangat besar.

Dengan menjadi sponsor utama liga 1 Indonesia, GO-JEK menerima manfaat (benefit) antara lain : pemasangan logo perusahaan di setiap kostum klub (jersey) peserta liga 1 Indonesia, pemasangan logo perusahaan di papan sponsor pinggir lapangan di setiap stadion peserta liga 1 Indonesia, iklan di televisi setiap ada pertandingan langsung dan ditampilkan logo perusahaan di tengah lapangan sebelum pertandingan di mulai (kick off) dan di jeda pertandingan antar babak.

Melihat peluang yang ada, dimana potensi pasar Indonesia yang sangat menjanjikan serta antusias masyarakat Indonesia terhadap olahraga sepak bola di tanah air sangat besar. Hampir di setiap daerah di Indonesia terdapat klub sepak bola profesional yang mengikuti kompetisi sepak bola yang dijalankan oleh PSSI selaku organisasi sepak bola nasional, ditambah basis-basis pendukung (supporter) fanatik klub. Iklim ekonomi di Indonesia yang semakin baik menjadi alasan utama GO-JEK memutuskan untuk menjadi sponsorship liga 1 indonesia bersama traveloka, sehingga dapat memperbaiki kinerja perusahaan di masa yang akan datang khususnya peningkatan pemesanan terhadap produkproduk GO-JEK melalui sponsorship terhadap olahraga yang paling populer saat ini.

Berdasarkan dari uraian di atas, maka penulis tertarik untuk melakukan penelitian dengan judul "Pengaruh Strategi Sponsorship PT.Gojek Indonesia di Liga 1 Indonesia Terhadap Keputusan Pemesanan Gojek di Kota Palembang”.

\section{KAJIAN TEORITIS}

\section{Sponsorship}

Definisi sponsorship menurut Duncan dalam H Farih (2015), Sponsorship adalah Dukungan keuangan dari sebuah organisasi, orang, atau kegiatan dalam pertukaran untuk Publisitas merek dan asosiasi. Sponsorship merupakan dukungan sumber daya (uang, manusia, peralatan) dari orang, organisasi atau perusahaan untuk mendapatkan keuntungan publisitas merek dan asosiasi berupa hak untuk menampilkan nama merek, logo, atau iklan dan pesan sebagai pendukung acara. pada :

Pelaksanaan kegiatan sponsorship yang dilakukan oleh perusahaan tergantung

1. Kesesuaian event sponsorship dengan konsumen sasaran.

2. Kesesuaian event sponsorship dengan event yang dilaksanakan.

3. Kesesuaian event sponsorship dengan produk.

4. Pesan yang disampaikan melalui sponsorship.

Dalam melakukan event sponsorship, ada faktor-faktor yang harus diperhatikan oleh perusahaan untuk menjamin keberhasilan kegiatan tersebut diantaranya : konsep 
acara, komunikasi pemasaran, kemampuan SDMHubungan baik dengan Event Organizer $(E O)$, besarnya budget, lokasi dan waktu, sasaran target yang ingin dituju, kesiapan team, koordinasi.

\section{Keputusan Pembelian (jasa)}

Menurut Kotler dan Keller (2009), keputusan pembelian adalah tindakan dari konsumen untuk mau membeli atau tidak terhadap produk. Sedangkan menurut Schiffman dan Kanuk (2009), keputusan pembelian yaitu pemilihan dari dua atau lebih alternatif pilihan keputusan pembelian, artinya bahwa seseorang bisa membuat keputusan, harus tersedia beberapa alternatif pilihan.Berdasarkan definisi diatas didapat kesimpulan bahwa keputusan pembelian merupakan penentuan keputusan membeli atau tidak antara beberapa alternatif dengan melakukan evaluasi pembelian sebelumnya.

Dalam pengambilan keputusan pembelian setiap konsumen harus melalui beberapa tahapan seperti yang di kemukakan oleh Kotler dan Keller (2009), proses pengambilan keputusan pembelian terdiri dari lima tahap yaitu :

1. Pengenalan Kebutuhan

2. Pencarian Informasi

3. Pengevaluasian Alternatif

4. Keputusan Pembelian

5. Perilaku Setelah Pembelian

Faktor-faktor yang mempengaruhi perilaku pembelian konsumen menurut Kotler dan Keller (2009), perilaku pembelian konsumen dipengaruhi oleh faktor budaya, sosial, pribadi dan psikologis. Berikut adalah faktor-faktor yang mempengaruhi perilaku konsumen : 1) Faktor budaya (budaya, subbudaya, dan kelas sosial sangat mempengaruhi perilaku pembelian konsumen); 2) Faktor sosial (Kelompok referensi, keluarga serta peran dan status adalah kategori dalam faktor sosial yang mempengaruhi perilaku konsumen). 3) Faktor Pribadi (Usia dan tahap siklus hidup, Pekerjaan, Keadaan ekonomi, Kepribadian dan Gaya Hidup). 4) Faktor Psikologis (motivasi, persepsi, pembelajaran dan memori).

\section{METODE PENELITIAN}

Objek penelitian dalam penelitian ini adalah konsumen GO-JEK di kota Palembang. Kantor cabang GO-JEK di kota Palembang berada di Jl.Basuki Rachmad no.1608 kelurahan 8 ilir, kecamatan IT II Palembang.

Dalam penelitian ini menggunakan desain penelitian deskriptif dengan pendekatan verifikatif. Desain penelitian deskriptif ini bertujuan untuk mendeskripsikan sifat atau karakteristik dari suatu gajala, peristiwa, kejadian yang terjadi saat ini, Juliansyah Noor (2015). Penelitian verifikatif menurut Suharsimi Arikunto (2014) adalah Penelitian yang pada dasarnya ingin menguji kebenaran melalui pengumpulan data dilapangan. Penelitian ini digunakan untuk menguji kebenaran dari hipotesis melalui pengumpulan data dilapangan. 
Dalam penelitian ini terdapat dua variabel. satu variabel independen (X) dan satu variabel dependen (Y). Variabel-variabel dalam penelitian ini diuraikan sebagai sebagai berikut :

Strategi Sponsorship sebagai variabel X (Variabel independen)

Keputusan pembelian sebagai variabel Y (Variabel dependen)

Operasional variabel penelitian ini dapat dijabarkan secara lengkap pada tabel berikut ini :

Tabel 2

Operasional Variabel

\begin{tabular}{|c|c|c|c|}
\hline Variabel & Konsep Variabel & Indikator & Skala \\
\hline $\begin{array}{l}\text { Sponsorship } \\
(\mathrm{X})\end{array}$ & $\begin{array}{l}\text { Sponsorship adalah suatu bentuk } \\
\text { dari promosi merek dengan cara } \\
\text { memberikan bantuan keuangan dari } \\
\text { sebuah organisasi, perorangan, atau } \\
\text { kegiatan yang menghubungkan } \\
\text { suatu merek dengan kegiatan olah } \\
\text { raga, hiburan, budaya, social (public } \\
\text { activity) yang menimbulkan } \\
\text { ketertarikan yang tinggi, dengan } \\
\text { memberikan timbal balik untuk } \\
\text { mengiklankan perusahaan menurut } \\
\text { Shimp (2007 : 589) dalam Zainal } \\
\text { Alim. }\end{array}$ & \begin{tabular}{|l} 
1. \\
Target penonton \\
yang ingin di \\
capai (Target \\
Audience Reach) \\
2. Kesesuaian \\
posisioning \\
perusahaan atau \\
merk (Compebility \\
With The \\
Company's Or \\
Brand \\
Positioning) \\
3. Isi pesan \\
(Message \\
Capacity)
\end{tabular} & Ordinal \\
\hline $\begin{array}{l}\text { Keputusan } \\
\text { Pembelian } \\
\text { (Jasa) } \\
\text { (Y) }\end{array}$ & $\begin{array}{l}\text { Menurut Kotler dan Keller (2009), } \\
\text { keputusan pembelian adalah } \\
\text { tindakan dari konsumen untuk mau } \\
\text { membeli atau tidak terhadap produk. }\end{array}$ & $\begin{array}{ll}\text { 1. } & \text { Kemampuan } \\
\text { pelanggan } \\
\text { terhadap } \\
\text { pembelian produk } \\
\text { 2. } \\
\text { Kepuasan } \\
\text { pelanggan } \\
\text { terhadap produk } \\
\text { yang ditawarkan } \\
\text { 3. Kebutuhan } \\
\text { pelanggan } \\
\text { terhadap produk. } \\
\text { 4. Manfaat produk } \\
\text { bagi pelanggan }\end{array}$ & Ordinal \\
\hline
\end{tabular}

Populasi dalam penelitian ini adalah seluruh warga kota palembang yang menggunakan layanan gojek. Teknik penarikan sampel pada penelitian ini menggunakan 
Cluster Sampling atau sampel berkelompok. Untuk menentukan wilayah yang dijadikan sampel, maka wilayah populasi terlebih dahulu ditetapkan secara Purposive, selanutnya menentukan jumlah sampel yang digunakan pada masing-masing daerah tersebut dengan menggunakan teknik Proportionate Stratified Random Sampling meningat jumlahnya yang bisa saja berbeda. Jumlah sampel sebanyak 272 orang, didapatkan berdasarkan dari tebel Isaac dan Michael dengan tingkat kesalahan 10\%. Sampel diambil dari 8 kecamatan di kota Palembang.

Data yang digunakan dalam penelitian ini adalah data primer. Proses pengumpulan data menggunakan Kuesioner/ Angket, skala yang digunakan dalam kuesioner ini adalah skala likert. Jenis data yang digunakan dalam penelitian ini adalah kualitatif, data diperoleh dengan menyebar link kuesioner online yang dibuat dengan menggunakan Google Docs Form (link: https://goo.gl/forms/X7LYwlwsiwh3mqeB3).

Uji validitas yaitu mengkorelasikan skor tiap butir dengan skor total yang merupakan jumlah setiap skor butir. Pengujian dilakukan melalui perbandingan antara $r$ hitung $>r_{\text {tabel }}$ maka kuesioner dinyatakan valid. Nilai $r$ tabel menggunakan rumus $(n-2)$ didapat dari tabel r Product Moment dengan taraf signiifikansi 10\% sebesar 0,0999. Jika korelasi antara butir dengan skor total $<0,0999$ maka butir dalam instrumen tersebut dinyatakan tidak valid.

Uji Reliabilitas merupakan pengujian yang digunakan untuk mengukur suatu kuesioner yang merupakan indikator dari variabel atau konstruk. Suatu instrumen dikatakan reliabel atau handal jika jawaban seseorang terhadap pernyataan-pertanyaan adalah konsisten atau stabil dari waktu ke waktu. Uji reliabilitas pada penelitian ini menggunakan Cronbach alpha diatas 0,60, Ghozali (2011).

Regresi linear sederhana dapat digunakan untuk memprediksikan seberapa jauh hubungan fungsional ataupun kausal satu variabel independen dengan satu variabel dependen. Pengujian hipotesis menggunakan Uji T, uji koefisien korelasi dan uji Koefisien determinasi. Pengujian dapat dilihat jika :

Jika $\mathrm{t}_{\text {hitung }}>\mathrm{t}_{\text {tabel}}$, maka $\mathrm{H}_{0}$ ditolak

Jika $\mathrm{t}_{\text {hitung }}<\mathrm{t}_{\text {tabel, }}$, maka $\mathrm{H}_{0}$ diterima

Uji Koefisien korelasi (R) digunakan untuk menerangkan kekuatan dan arah hubungan antara variabel independen dengan variabel dependen, Sugiyono( 2012 : 184). Uji Koefisien determinasi (R2) digunakan untuk mengetahui besarnya presentase variasi dalam variabel bebas terhadap model dapat diterangkan oleh variabel terikat. 


\section{HASIL PENELITIAN DAN PEMBAHASAN}

\section{Karakteristik Responden}

\section{Karakteristik Responden Berdasarkan kecamatan}

Tabel 3

Karakteristik Responden Berdasarkan Kecamatan

\begin{tabular}{|l|l|r|r|}
\hline No & Kecamatan & Responden & Persentase \\
\hline 1 & Seberang Ulu I & 46 & $17 \%$ \\
\hline 2 & Seberang Ulu II & 26 & $9,5 \%$ \\
\hline 3 & Ilir Barat I & 35 & $13 \%$ \\
\hline 4 & Ilir Timur II & 43 & $16 \%$ \\
\hline 5 & Kalidoni & 29 & $11 \%$ \\
\hline 6 & Sako & 24 & $8 \%$ \\
\hline 7 & Sukarami & 43 & $16 \%$ \\
\hline 8 & Alang-alang Lebar & 26 & $9,5 \%$ \\
\hline Jumlah & 272 & $100 \%$ \\
\hline
\end{tabular}

Sumber : Pengolahan Data Primer (2018)

Responden terdiri dari 8 kecamatan mewakili kota Palembang antara lain kecamatan Seberang Ulu I, Seberang Ulu II, Ilir Barat I, Ilir Timur II, Kalidoni, Sako, Sukarami dan Alang-alang Lebar.

\section{Karakteristik Responden Berdasarkan usia}

\section{Tabel 4}

Karakteristik Responden Berdasarkan usia

\begin{tabular}{|c|c|c|c|}
\hline kelas & Interval & $\begin{array}{c}\text { Frekuensi } \\
\text { (Orang) }\end{array}$ & $\begin{array}{c}\text { Persentase } \\
(\%)\end{array}$ \\
\hline 1 & $18-20$ & 64 & 23,5 \\
\hline 2 & $21-23$ & 87 & 32 \\
\hline 3 & $24-26$ & 46 & 16,9 \\
\hline 4 & $27-29$ & 23 & 8,5 \\
\hline 5 & $30-32$ & 18 & 6,6 \\
\hline 6 & $33-35$ & 21 & 7,7 \\
\hline 7 & $36-38$ & 13 & 4,8 \\
\hline \multicolumn{2}{|c|}{ Jumlah } & 272 & 100 \\
\hline
\end{tabular}

Sumber : Pengolahan Data Primer (2018)

Dari data tersebut, mayoritas responden pengguna GO-JEK dengan rentan usia 18-23 tahun sebanyak 151 orang $(55,5 \%)$ dari seluruh total responden. 


\section{Karakteristik Responden Berdasarkan Pekerjaan \\ Tabel 4}

Karakteristik Responden Berdasarkan pekerjaan

\begin{tabular}{|c|c|c|}
\hline Pekerjaan & $\begin{array}{c}\text { Frekuensi } \\
\text { (Orang) }\end{array}$ & $\begin{array}{c}\text { Persentase } \\
(\mathbf{\%})\end{array}$ \\
\hline Buruh & 1 & 0,4 \\
\hline Karyawan Swasta & 127 & 46,7 \\
\hline PNS & 41 & 15,1 \\
\hline Pelajar / Mahasiswa & 91 & 33,5 \\
\hline Lain-lain & 12 & 4,4 \\
\hline Jumlah & $\mathbf{2 7 2}$ & $\mathbf{1 0 0}$ \\
\hline
\end{tabular}

Sumber : Pengolahan Data Primer (2018)

Dari data tersebut, mayoritas responden pengguna GO-JEK digunakan oleh Karyawan Swasta dan Pelajar / Mahasiswa sebanyak 218 orang $(80,2 \%)$ dari seluruh responden.

\section{Pengujian Validitas}

\section{Tabel 5}

Hasil uji validitas variabel sponsorship $(X)$

$(n=272, \alpha=10 \%, r$ tabel $=0,0999)$

\begin{tabular}{|l|r|r|c|}
\hline No. Pernyataan & r hitung & r tabel & Keterangan \\
\hline Pernyataan 1 & 0,739 & 0,0999 & Valid \\
\hline Pernyataan 2 & 0,781 & 0,0999 & Valid \\
\hline Pernyataan 3 & 0,637 & 0,0999 & Valid \\
\hline Pernyataan 4 & 0,612 & 0,0999 & Valid \\
\hline Pernyataan 5 & 0,694 & 0,0999 & Valid \\
\hline Pernyataan 6 & 0,702 & 0,0999 & Valid \\
\hline Pernyataan 7 & 0,650 & 0,0999 & Valid \\
\hline Pernyataan 8 & 0,799 & 0,0999 & Valid \\
\hline
\end{tabular}

Sumber : Pengolahan Data Primer (2018)

\section{Tabel 6}

Hasil uji validitas variabel keputusan pemesanan (Y)

$$
(\mathrm{n}=\mathbf{2 7 2}, \alpha=10 \%, \mathrm{r} \text { tabel }=0,0999)
$$

\begin{tabular}{|l|r|r|c|}
\hline No. Pernyataan & r hitung & r tabel & Keterangan \\
\hline Pernyataan 9 & 0,784 & 0,0999 & Valid \\
\hline Pernyataan 10 & 0,652 & 0,0999 & Valid \\
\hline Pernyataan 11 & 0,580 & 0,0999 & Valid \\
\hline Pernyataan 12 & 0,803 & 0,0999 & Valid \\
\hline Pernyataan 13 & 0,929 & 0,0999 & Valid \\
\hline Pernyataan 14 & 0,920 & 0,0999 & Valid \\
\hline Pernyataan 15 & 0,916 & 0,0999 & Valid \\
\hline Pernyataan 16 & 0,910 & 0,0999 & Valid \\
\hline Pernyataan 17 & 0,857 & 0,0999 & Valid \\
\hline
\end{tabular}

Sumber : Pengolahan Data Primer (2018) 
Berdasarkan tabel di atas, diketahui pernyataan pada variabel Sponsorship (X) sebanyak 8 pernyataan dan 9 butir pernyataan variabel Keputusan Pemesanan (Y) dinyatakan valid atau dapat dipergunakan sebagai alat untuk mengumpulkan data.

\section{Pengujian Reliabilitas}

\section{Tabel 7}

\section{Hasil uji reliabilitas variabel sponsorship (X)}

\begin{tabular}{|c|c|c|}
\hline \multicolumn{3}{|c|}{ Reliability Statistics } \\
\hline $\begin{array}{c}\text { Cronbach's } \\
\text { Alpha }\end{array}$ & $\begin{array}{c}\text { Cronbach's } \\
\text { Alpha Based } \\
\text { on } \\
\text { Standardized } \\
\text { Items }\end{array}$ & $\begin{array}{l}\mathrm{N} \text { of } \\
\text { Items }\end{array}$ \\
\hline ,771 & ,894 & 9 \\
\hline
\end{tabular}

Sumber : Pengolahan Data Primer (2018)

\section{Tabel 8}

\section{Hasil uji reliabilitas variabel keputusan pemesanan (Y)}

Sumber : Pengolahan Data Primer (2018)

\begin{tabular}{|c|c|c|}
\multicolumn{3}{|c|}{ Reliability Statistics } \\
\hline & $\begin{array}{c}\text { Cronbach's } \\
\text { Alpha Based } \\
\text { on } \\
\text { Cronbach's } \\
\text { Alpha }\end{array}$ & \\
\hline Standardized & N of \\
Items & Items \\
\hline, 782 &, 936 & 10 \\
\hline
\end{tabular}

Berdasarkan hasil pengujian reliabilitas untuk variabel variabel Sponsorship (X) didapat nilai koefisien Cronbach's Alpha sebesar 0,771 dan Keputusan Pemesanan (Y) sebesar 0,782 nilai tersebut lebih besar dari 0,6 sehingga item pernyataan untuk variabel Sponsorship (X) dan Keputusan Pemesanan (Y) dapat dinyatakan reliabel.

\section{Uji Analisis Regresi Linear Sederhana}

Tabel 9

Pengujian analisis regresi linier sederhana

Coefficients $^{\mathrm{a}}$

\begin{tabular}{|c|c|c|c|c|c|}
\hline \multirow[b]{2}{*}{ Model } & \multicolumn{2}{|c|}{$\begin{array}{c}\text { Unstandardized } \\
\text { Coefficients }\end{array}$} & \multirow{2}{*}{\begin{tabular}{|c|}
$\begin{array}{c}\text { Standardized } \\
\text { Coefficients }\end{array}$ \\
Beta \\
\end{tabular}} & \multirow[b]{2}{*}{$\mathrm{T}$} & \multirow[b]{2}{*}{ Sig. } \\
\hline & B & Std. Error & & & \\
\hline (Constant) & 26,177 & 1,949 & & 13,427 &, 000 \\
\hline$X$ &, 100 & ,075 &, 081 & 1,332 &, 184 \\
\hline
\end{tabular}

a. Dependent Variable: y

Sumber : Pengolahan Data Primer (2018) 
Berdasarkan tabel di atas, maka dapat diperoleh nilai persamaan regresi suatu model dengan melihat pada Unstandardized Coefficients nilai-nilai pada kolom B. Adapun persamaan regresi linier sederhana dalam penelitian ini sebagai berikut :

$$
Y=26,177+0,1 X+e
$$

\section{Uji T}

Menggunakan uji dua arah (two tail) pada tingkat signifikansi $10 \%(\alpha=0,1)$ dengan derajat bebas $(\mathrm{df}=\mathrm{n}-\mathrm{k})$ dimana $\mathrm{n}$ adalah jumlah responden dan $\mathrm{k}$ adalah jumlah variabel dalam penelitian ini, didapat $(\mathrm{df}=272-2=270) \mathrm{t}$ tabel $1,65, \mathrm{t}$ hitung didapat sebesar 1,332 di lihat pada kolom $t$ tabel pengujian regresi . Dari data tersebut didapat kesimpulan bahwa $\mathrm{t}_{\text {hitung }}>\mathrm{t}_{\text {tabel }}(1,332<1,65)$ yang artinya $\mathrm{H}_{0}$ di terima atau tidak terdapat pengaruh strategi sponsorship PT. Gojek Indonesia di liga 1 Indonesia terhadap keputusan pemesanan GOJEK di kota Palembang.

Jika dilihat dari nilai signifikansi $(0,184>0,05)$ maka, dalam penelitian ini diktahui pengaruh yang diberikan oleh strategi sponsorship terhadap keputusan pemesanan GOJEK di kota Palembang tidak signifikan.

\section{Koefisien Korelasi dan Koefisien Determinasi}

Tabel 10

Koefisien korelasi dan koefisien determinasi

\begin{tabular}{|l|c|r|r|r|}
\hline \multicolumn{5}{|c|}{ Model Summary } \\
Model & $\mathrm{R}$ & R Square & $\begin{array}{c}\text { Adjusted R } \\
\text { Square }\end{array}$ & $\begin{array}{c}\text { Std. Error of } \\
\text { the Estimate }\end{array}$ \\
\hline 1 &, $081^{\mathrm{a}}$ &, 007 &, 003 & 8,51720 \\
\hline
\end{tabular}

a. Predictors: (Constant), $\mathrm{x}$

Sumber : Pengolahan Data Primer (2018)

Diketahui nilai koefisien korelasi sebesar 0,081 berkisar antara 0,00 - 0,199 didapat kesimpulan bahwa hubungan antara variabel Sponsorship dan Keputusan Pemesanan Sangat Rendah menurut Sugiono (2012:184). Nilai koefisien Determinasi $R$ Square adalah sebesar 0,007 di mana angka tersebut menunjukkan bahwa Sponsorship mampu mempengaruhi keputusan pemesanan sebesar 0,7\% sedangkan 99,3\% dipengaruhi oleh variabel lain yang tidak termasuk dalam penelitian ini.

\section{Pembahasan}

Pada penelitian ini dilakukan pengukuran pengaruh sponsorship terhadap keputusan pemesanan GO-JEK di kota Palembang, yaitu dengan variabel independen sponsorship dan variabel dependen pada penelitian ini adalah keputusan pemesanan atau keputusan pembelian (jasa). Sponsorship adalah penyediaan sumberdaya (uang, manusia, peralatan) secara langsung oleh sebuah organisasi (sponsor) kepada seorang individu, suatu badan yang berwenang agar dapat mengikuti suatu kegiatan yang akan dilakukan untuk mendapatkan suatu keuntungan yang dimaksud dalam strategi promosi pihak 
sponsor dan dimana dapat pula dinyatakan dalam tujuan perusahaan, pemasaran atau media. Sedangkan keputusan pembelian adalah tindakan dari konsumen untuk mau membeli atau tidak terhadap produk.

Berdasarkan beberapa uji kuantitatif yang telah dilakukan, di ketahui jika sponsorship tidak memiliki pengaruh terhadap keputusan pemesanan GO-JEK di kota Palembang. Hal tersebut dapat dilihat dari nilai uji $\mathrm{t}$, dimana nilai $\mathrm{t}$ hitung $<\mathrm{t}$ tabel $(1,332<$ 1,65) angka tersebut menunjukkan tidak adanya pengaruh strategi sponsorship PT. Gojek Indonesia di liga 1 Indonesia terhadap keputusan pemesanan GO-JEK di kota Palembang.

Dengan adanya sponsorship yang dilakukan GO-JEK pada Liga 1 Indonesia, tidak memberikan pengaruh terhadap proses pengambilan keputusan konsumen dalam melakukan pemesanan GO-JEK di kota Palembang seperti yang tertulis pada uji t diatas, hal tersebut juga di jelaskan pada uji regresi yang telah dilakukan.

Pada uji regresi linier sederhana menunjukkan angka sebesar $Y=26,177+$ $0,1 X+e$. Berdasarkan hasil uji regresi tersebut diketahui jika tidak terdapat variabel sponsorship $(\mathrm{X}=0)$ maka keputusan konsumen memesan GO-JEK sebesar 26,177 satuan, hal tersebut menunjukkan bahwa kebutuhan konsumen akan layanan GO-JEK akan selalu ada sejumlah angka tersebut walau tanpa adanya sponsorship. Sedangkan nilai koefisiennya menunjukkan angka 0,1 satuan yaitu dengan adanya sponsorship akan meningkatkan keputusan konsumen dalam menggunakan layanan GO-JEK, setiap penambahan 1 satuan sponsorship maka akan meningkatkan keputusan pemesanan GOJEK di kota Palembang sebesar 0,1 satuan. Berdasarkan angka tersebut dapat dilihat variabel sponsorship berpengaruh positif terhadap variabel keputusan pemesanan, dengan adanya strategi sponsorship maka akan menambah peluang warga memesan layanan GOJEK di kota Palembang.

Dengan hasil yang di dapatkan diatas ada beberapa faktor yang mempengaruhi GOJEK dalam menjalankan strategi sponsorship nya di Liga 1 Indonesia antara lain : konsep acara, komunikasi pemasaran, kemampuan SDM, hubungan baik dengan event organizer $(E O)$, besarnya budget, lokasi dan waktu, sasaran target yang ingin dituju, kesiapan team dan koordinasi.

Hasil tersebut diprkuat juga oleh hasil koefisien korelasi dan koefisien determinasi yang di dapat, menunjukkan keeratan dan besarnya pengaruh sponsorship tersebut dalam mempengaruhi keputusan pemesanan layanan GO-JEK di kota Palembang. Hasil yang didapatkan dari perhitungan koefisien korelasi menunjukkan hasil sebesar 0,081 angka tersebut menunjukkan keeratan hubungan antara variabel Sponsorship dan Keputusan Pemesanan, angka tersebut berkisar antara 0,00 - 0,199 yang menandakan hubungan antara variabel Sponsorship dan keputusan pemesanan sangat rendah.

Sedangkan angka yang dihasilkan dari koefisien determinasi sebesar 0,007 (0,7\%) angka tersebut menjelaskan berapa besar dampak atau kemampuan Sponsorship dalam memberikan pengaruh terhadap keputusan pemesanan GO-JEK di kota Palembang. 
Dari hasil koefisien korelasi dan koefisien determinasi tersebut dapat di simpulkan bahwa strategi Sponsorship tidak terlalu memberi pengaruh terhadap keputusan pemesanan GO-JEK di kota Palembang. Hal tersebut di karenakan ada faktor-faktor atau variabel lain yang mempengaruhi keputusan pemesanan GO-JEK di kota Palembang yang tidak di teliti dalam penelitian ini, seperti kualitas pelayanan, metode pembayaran dan banyaknya variasi produk yang ditawarkan.

Dari hasil penelitian diatas dapat disimpulkan bahwa pengaruh strategi sponsorship PT. Gojek Indonesia di liga 1 Indonesia terhadap keputusan pemesanan GO-JEK di kota Palembang tidak memiliki pengaruh yang signifikan karena keputusan pemesanan GOJEK di kota Palembang dipengaruhi oleh faktor - faktor lain yang lebih dominan seperti kualitas pelayanan, metode pembayaran dan banyaknya variasi produk yang ditawarkan.

\section{KESIMPULAN DAN SARAN}

\section{Kesimpulan}

Responden dalam penelitian ini sebanyak 272 responden yang merupakan konsumen GO-JEK di kota Palembang. Setelah dilakukan beberapa tahap pengujian peneliti di dapat kesimpulan :

1. Dari analisis regresi linear sederhana diperoleh persamaan $Y=26,177+0,1 X$ artinya bahwa strategi sponsorship berpengaruh positif terhadap keputusan pemesanan GOJEK di kota Palembang. Dengan nilai konstanta sebesar 26,177 artinya jika tidak ada Sponsorship maka keputusan pemesanan tetap sebesar 26,177 dan nilai koefisien regresi Sponsorship (X) sebesar 0,1 artinya setiap ada penambahan 1 satuan Sponsorship maka akan meningkatkan keputusan pemesanan GO-JEK sebesar 0,1 satuan.

2. Berdasarkan hasil uji hipotesis terlihat dari nilai $\mathrm{t}_{\text {hitung }}$ sebesar 1,332 lebih kecil dari $\mathrm{t}$ tabel sebesar 1.65 yang artinya $\mathrm{H}_{0}$ diterima dan $\mathrm{H}_{1}$ ditolak, atau tidak terdapat pengaruh strategi Sponsorship PT. Gojek Indonesia di liga 1 Indonesia terhadap keputusan pemesanan GO-JEK di kota Palembang.

\section{Saran}

Karena kecilnya pengaruh sponsorship dalam mempengaruhi keputusan pemesanan maka disarankan kepada PT. Gojek Indonesia (GO-JEK) agar mempertimbangkan strategi promosi lain yang memiliki kesesuaian dengan konsep atau tema dari GO-JEK itu sendiri. Bagi peneliti selanjutnya disarankan untuk menambahkan variabel lain dan memperluas wilayah penelitian karena akan menambah temuan-temuan baru dari penelitian sebelumnya.

\section{DAFTAR PUSTAKA}

A Shimp, Terence. 2007. Periklanan Promosi ( Aspek Tambahan Komunikasi Pemasaran Terpadu). Jilid I. edisi Terjemahan. Erlangga: Jakarta. 
Ali, Hasan . 2013. Marketing dan Kasus-Kasus Pilihan. CAPS (Center For Academic Publishing Service): Yogyakarta.

Alma, Buchari. 2004. Manajemen Pemasaran dan Pemasaran Jasa. Cetakan Keenam. Alfabeta: Bandung.

Arikunto, Suharsimi. 2014. Prosedur Penelitian Suatu Pendekatan Praktik. Rineka Cipta : Jakarta.

Assauri, Sofjan. 2010. Manajemen Pemasaran: Dasar, Konsep \& Strategi. Raja Grafindo Persada: Jakarta.

Daryanto. 2011. Manajemen Pemasaran. Sari Kuliah. Satu Nusa: Bandung.

Ghozali, Imam. 2011. Aplikasi Analisis Multivariate dengan Program SPSS. Badan Penerbit Universitas Diponegoro: Semarang.

Kotler, Philip dan Gary Armstrong. 2012. Prinsip-prinsip Pemasaran. Edisi 13. Jilid 1. Erlangga: Jakarta

Kotler, Philip dan Kevin Lane Keller. 2009. Manajemen Pemasaran. Edisi 13. Jilid 1. Erlangga: Jakarta

Lupioadi, Rambat. 2013. Manajemen pemasaran Jasa. Salemba Empat: Jakarta

Noor, Juliansyah. 2015. Metodologi Penelitian. Prenadamedia Grup: Jakarta

Peter dan J. Olson. 2009. Consumer Behavior and Marketng Strategy. Edisi kedua belas. Penerbit Gramedia Pustaka Utama: Jakarta

Sanusi, Anwar. 2011. Metode Penelitian Bisnis. Salemba Empat: Jakarta

Schiffman, L, G. dan, L. L. Kanuk. 2009. Persepsi kualitas, Consumer Behavior. Perason Prestice Hall: New Jersey

Sugiyono. 2012. Metode Penelitian Kuantitatif Kualitatif dan R\&D. Alfabeta: Bandung 